\title{
Hemoglobin SC Disease: Phenotypic Variability and Therapeutic Options
}

\author{
Bindu K Sathi* \\ Department of Pediatric Hematology and Oncology, Valley Children's Hospital, USA
}

*Corresponding author: Bindu K Sathi, Department of Pediatric Hematology and Oncology, Valley Children's Hospital, Madera, California, USA.

To Cite This Article: Bindu K Sathi, Hemoglobin SC Disease: Phenotypic Variability and Therapeutic Options. 2020 - 7(5). AJBSR.MS.ID.001194. DOI: 10.34297/AJBSR.2020.07.001194.

Received: 眥 February 19, 2020; Published: 䟧 February 28, 2020

\begin{abstract}
Mutation in the Beta Globin Gene (HBB) leads to the formation of Hemoglobin S (HbS) and Hemoglobin C (HbC). Co-inheritance of HbS and HbC causes hemoglobin SC disease, a form of hemolytic anemia with a myriad of clinical manifestations. Valine replaces glutamic acid in the 6th position (Glu 6Val) to form HbS and Lysine replaces glutamic acid (Glu6Lys) in HbC. The interaction of HbC with HbS increases the propensity of red blood cells to sickle leading to microvascular occlusion and down-stream end organ complications.

Both $\mathrm{HbS}$ and $\mathrm{HbC}$ are present in approximately equal levels in $\mathrm{HbSC}$ red blood cells. It is interesting to note that Sickle cell trait and Hemoglobin $\mathrm{C}$ trait do not produce severe disease. However, the combination of $\mathrm{HbS}$ and $\mathrm{HbC}$ can produce a moderately severe disease than the sum of the effects of $\mathrm{HbS}$ and $\mathrm{HbC}$ disease. This is because the presence of $\mathrm{HbC}$ enhances the cellular dehydration of the red blood cell resulting in a more profound phenotype than their respective traits. Most of the evidence-based guidelines in Sickle Cell Disease (SCD) come from the Cooperative Study of Sickle Cell Disease (CSSD), which was undertaken more than 30 years ago, and there is paucity of data to this date regarding optimal management of hemoglobin SC disease [1,2].
\end{abstract}

Keywords: Hemoglobin SC disease (HbSC), Pain crisis, Splenic sequestration, Priapism, Newer therapeutics, Homozygous Sickle Cell Disease, RBC aggregation, Mononuclear cells, neovascularization, Analgesia

\section{Introduction}

Hemoglobin SC disease (HbSC) is the second most common hemoglobin disorder after hemoglobin SS disease (HbSS), with a world-wide prevalence of 55,000 new babies born with the disease every year [3]. It affects about $2 \%$ of the population in western Africa, with approximately $25 \%$ in Northern Ghana. Approximately, $30 \%$ of the patients suffering from sickle cell disorder have HbSC genotype and the 1 in 6,173 babies born in USA are affected by the disease [4]. Despite the relatively high prevalence, our understanding of $\mathrm{HbSC}$ disease and management of this condition comes from extrapolation of data from Homozygous Sickle Cell Disease (SCD) [1]. It is important to understand that HbSC is a distinct entity from $\mathrm{HbSS}$ with marked clinical variability in disease presentation. Typically, clinical manifestations are mostly less severe than SCD and life expectancy is higher than for SCD [4].

\section{History of Hemoglobin SC disease}

In 1950, Itano and Neel [5], using a method of paper electrophoresis described Hemoglobin C5. Prior to this paper, Pauling had showed the use of this technique in identifying abnormal hemoglobin [6-9]. In 1951, Kaplan et al. [10] had described the clinical manifestations of the disease in 3 patients with HbSC10. In 1961, cases of HbSC disease were studied and their clinical presentation and findings were reported [11]. Since then, our understanding of the disease has improved but several paradoxes remain.

\section{Genetics of Hemoglobin SC Disease ( $\alpha 2 \beta 2$ 6Val, $\alpha 2 \beta 2$ 6Lys)}

$\mathrm{HbC}$ is caused by a mutation in the seventh codon of the HBB gene [HBB: c. 19G >A 9p. Glu 6Lys)]. The $\beta$ s allele described in 
Sickle cell disease is associated with different $\beta$ s haplotypes and are named after the region of origin. These include 4 major haplotypes originating from Africa (Senegal, Benin, Bantu and Cameroon) and one Arabian- Indian Haplotype [12,13]. Of these $\beta$ s haplotypes, Bantu is the most severe and Senegalese is the least severe one. In addition to the anthropological significance of the origins of the $\beta$, the different haplotypes have been found to modify the severity of the sickle cell disease. The $\beta c$ haplotypes have been described by Boehm et al as I, II and III and has not been found to modify disease severity $[12,13]$.

\section{Hemoglobin C Origin, Selection and Malaria Resistance}

Polymorphic frequency of $\mathrm{HbC}$ gene mutation has been noted (at a frequency of greater than 1\%) in western Africa. Protection from Malaria is conferred in $\mathrm{HbC}$ individuals with $29 \%$ reduction in malaria in the $\mathrm{HbC}$ heterozygotes and 93\% reduction in homozygotes [14]. This reduction is hypothesized to be due to the interference in the red cell membrane breakdown in the late schizont phase and release of merozoites into the peripheral circulation [15].

\section{Pathophysiology of Hemoglobin SC Disease}

HbSC Red Blood Cells (RBCs) typically contain equal amounts of $\mathrm{HbC}$ and $\mathrm{HbS}$ and an extremely low level of $\mathrm{HbF}$ (1-3\%). The pathogenesis of HbSC is due to the interaction between $\mathrm{HbC}$ and $\mathrm{HbS}$ which influences $\mathrm{HbS}$ polymer formation. Cellular dehydration caused by the abnormal membrane K-CL Cotransporter (KCC) function also plays a key role in the pathogenesis of this disease $[16,17]$. Dehydration of the RBCs leads to increased HbS concentration in the cells setting up an environment to cause sickling. Oxygenated HbSC red blood cells show exaggerated potassium efflux, which is dependent on the activity of the Cl- ions, and there is some evidence suggesting that $\mathrm{HbC}$ molecules interact with KCC molecules on the red cell membrane mediating the effects $[18,19]$. Cellular dehydration increases the MCHC sufficiently that even at lower $\mathrm{HbS}$ concentration $\mathrm{HbS}$ polymerization occurs. Cellular analysis has revealed that HbSC RBCs tend to have higher concentrations of $\mathrm{S}$ and increased hemoglobin compared to AS counterparts which contributes to the pathogenesis [20]. Altered hemorheological parameters have also been noted in HbSC disease, which contributes to disease pathology [21]. This includes increased blood viscosity, decreased RBC deformability and increased RBC aggregation. Decreased deformability of red blood cells was noted in HbSC retinopathy [22,23]. Impaired red cell deformability and blood hyperviscosity has been noted in patients with HbSC disease with retinopathy and otological complications, respectively [23].

At moderate to high $\mathrm{HbS}$ concentration, long, rigid polymers of $\mathrm{HbS}$ is formed leading to microvascular obstruction [16]. At high concentration, $\mathrm{HbC}$ forms tetragon crystals in oxygenated state, but these dissolve quickly in deoxygenated state [16]. It has also been found that $\mathrm{HbS}$ accelerates $\mathrm{HbC}$ crystallization in oxygenated state. This phenomenon may contribute to disease pathology, but the exact mechanism is still unknown. $\mathrm{HbF}$ leads to reduction in $\mathrm{HbC}$ crystal formation and $\mathrm{HbS}$ polymerization and thus, is an important therapeutic target in this condition.

\section{Genetic Modifier of Hemoglobin SC Disease}

Co-inheritance of alpha thalassemia gene deletions decreases HbS polymerization and can therefore modify the severity of the disease. In a cross-sectional observational study, Powars et al. [24] reported that patients with 2 HBA1/2 gene deletions had lesser prevalence of painful crisis, osteonecrosis, gall bladder disease and retinopathy. Patients also had lesser clinical outcomes like multiorgan failure [24].

It has been recently reported that co-inheritance of $\alpha$-thalassemia decreases the risk of acute splenic sequestration in HbSC disease [25]. Unlike its counterpart the homozygous SS disease, the genetic modifiers of disease severity in $\mathrm{HbSC}$ have not been extensively studied.

\section{Hematological Profile of Hemoglobin SC Disease}

Chronic Hemolytic anemia is a hall mark of HbSC disease and individuals with HbSC disease have higher hemoglobin and lower absolute reticulocyte count compared to Sickle Cell Disease patients [26]. More than $70 \%$ of the patients have anemia, but typically the hemoglobin tends to be higher, Mean Corpuscular Volume (MCV) is lower and co-inheritance of alpha thalassemia trait further reduces the MCV. Elevated WBC count that is frequently noted in HbSS is not usually seen in HbSC individuals. Splenomegaly and clinical signs of hypersplenism may be seen in children and adults with HbSC. Thrombocytopenia may occur in subjects with hypersplenism. Target cells may be seen in peripheral smear due to the increased cellular surface area. Distorted elongated cells may be seen due to $\mathrm{HbC}$ crystal formation.

Irreversible sickle cells are rare, but blood viscosity is higher compared to HbSS individuals [16]. Routinely, HbSC individuals were found to have higher hemoglobin levels than HbSS subjects, lower total leukocyte, granulocyte, monocyte, and lymphocyte counts. Platelets decreased with age but not significantly, instead of increasing as among HbSS patients. Mononuclear cells were generally like racial and ethnically matched controls except for CD8+HLA-DR+ counts resembling HbSS [27].

Homozygous SS disease is also a condition of impaired peripheral macrovascular and microvascular responses. In studies, microvascular dilatory reserve was decreased in HbSC disease, but the macrovascular function was largely preserved in these subjects $[28,29]$. Although $\mathrm{HbSC}$ individuals have increased viscosity of blood, it appears that Nitric Oxide (NO) dependent vascular function and elasticity of vessels are preserved. This may play a 
role in normalization of vascular resistance and reduction of vasoocclusive crisis in these patients [30].

\section{Hemorheological Profile of Red Blood Cells in Hemoglobin SC Disease}

Individuals with $\mathrm{HbSC}$ usually contain 50\% Sickle Cell hemoglobin (HbS) ( $\alpha 2 \beta 2$ 6Glu-Val) and 50\% C Hemoglobin (HbC) $\alpha 2 \beta 26 \mathrm{Glu}$-Lys and no HbA $\alpha 2 \beta 26 \mathrm{Glu}$. This is an important contrast to the other heterozygous state of sickle cell trait ( $\mathrm{HbAS})$, where the $\mathrm{HbA}$ concentration is about $60 \%$ and $\mathrm{HbS}$ concentration is about $40 \%$. Another difference is that the Mean Corpuscular Hemoglobin Concentration (MCHC) is higher in HbSC compared to HbAS or HbSS21. The causal factors that lead to clinical heterogeneity, as well as increased severity of symptoms in some individuals with HbSC, are not fully known.

Some of the pathophysiology of HbSC could be attributed to the abnormal rheological profile of the blood. Blood viscosity is the highest in HbSC compared to HbSS and HbAA groups. The RBC deformability, as measured by RBC elongation index, is higher in AA group compared to SC and SS groups. RBC aggregation index (extend of RBC aggregation) was lowest for SC compared to SS and $\mathrm{AA}$ whereas the RBC disaggregation threshold was higher in the SC and SS groups compared to AA subjects [21,31].

Additionally, in $50: 50 \mathrm{HbS} / \mathrm{HbC}$ mixtures, polymerization of hemoglobin is about 15 times more rapid than in $40: 60 \mathrm{HbS} / \mathrm{HbA}$ mixtures at the same total hemoglobin concentration [20]. It has also been noted that higher concentration of hemoglobin occurs from the early stages of production of HbSC red blood cells which is presumed to contribute to the disease pathology. Together, these findings indicate that increased blood viscosity and abnormal blood rheology in HbSC individuals contribute to disease pathology.

\section{Phenotypic Manifestations of Hemoglobin SC Disease}

Compared to HbSS, HbSC produces a less severe disease phenotype even though it has been brought to attention that some severe symptoms are associated with $\mathrm{HbSC}$ in recent years. Historically, some of the disease manifestations like splenic sequestration, acute chest syndrome, osteonecrosis and retinitis proliferans occur in equal or increased frequency in $\mathrm{HbSC}$ disease. Incidence and severity of certain complications varies with $\mathrm{C}$ haplotype, associated S haplotype and co-inheritance of alpha gene mutation [24].

\section{Pain Crisis in Hemoglobin SC Disease}

Like HbSS, painful crisis is the commonest disease manifestation in SC Disease. More than 50\% of the people with HbSC suffer from painful episodes or crisis [24]. In another study, painful vasoocclusive crisis was the most prevalent clinical symptom, followed by acute chest syndrome and priapism [32]. Prevention strategies include prevention of dehydration, hypoxia and treatment includes hydration, analgesia and oxygenation. Reduction of cellular dehydration and blood viscosity are important targets for prevention of pain crisis.

Control of pain with strategies including judicious use of NSAIDS and opioids has been recommended. Renal function needs to be monitored during the use of NSAIDS. Use of targeted therapies including use of K-CL co-transporter inhibitor magnesium to prevention cellular dehydration have not demonstrated efficacy in modifying pain episodes [33,34]. Role of phlebotomy in decreasing the pain crisis has been described in a limited case series $[34,35]$.

\section{Ocular Disease Manifestations in Hemoglobin SC Disease}

Retinitis Proliferans (RP) or proliferative sickle cell retinopathy is a common complication of HbSC disease, occurring in 30-70\% of the patients with the disease compared to $3 \%$ of HbSS patients [36-38]. RP is due to excessive retinal blood growth and the peak incidence is in the 3rd or 4th decade. The hypothesized reason for retinopathy in SC disease that minimal oxygenation required for angiogenesis downstream of occlusion is maintained in SC disease, whereas, in HbSS there is ischemic infarction and lack of oxygenation prevents neovascularization. Hyperviscosity seen in HbSC may also play a role in the neovascularization. Proliferative neovascularization can lead to vitreous hemorrhage and traction retinal detachment [38]. Other manifestations include acute vision loss due to occlusion of ocular structures. Central retinal artery occlusion is typically rare in HbSC disease [39].

In a comparative study of $\mathrm{HbSS}$ and $\mathrm{HbSC}$ patients, higher prevalence of severe Proliferative Sickle Cell Retinopathy (PSCR) has been noted in SC patients. The rates of Stage 3, 4, and 5 PSCR was found to be $38 \%, 6.4 \%$ and $8 \%$ and $15.7 \%, 1.3 \%$ and $1 \%$, for $\mathrm{HbSC}$ and $\mathrm{HbSS}$, respectively. Severe PSCR was independently associated with increasing age, lower ferritin, tinnitus and hearing deficits and pulmonary disease [37,39].

Screening for ophthalmological complications needs to be undertaken at least by 10 years of age per NHLBI guidelines and earlier if there are vision associated clinical symptoms. Treatment includes sickle cell disease control with transfusion, even though high quality data is lacking currently to support this. Local treatment with diathermy, cryotherapy [40] and transpupillary or trans-scleral diode laser photocoagulation [37]. In some cases, red cell exchange transfusion has been found to halt the progression of retinitis proliferans [41].

\section{Manifestations in Hemoglobin SC Disease}

Approximately $30 \%$ of the individuals with $\mathrm{HbSC}$ will have otological disorders [32]. Sensorineural deafness is a common reported finding in HbSC, and prevalence seems to be higher than in HbSS patients. Labyrinthine hemorrhage is a common cause of sensorineural deafness and seems to be associated with 
proliferative retinopathy. Altered capillary hemodynamics, vasoocclusion and reperfusion injury involving the labyrinthine blood vessels has been speculated to play a role in the pathology [42].

\section{Splenic Function in Hemoglobin SC Disease}

When compared to HbSS disease, hypersplenism is more prevalent in HbSC individuals. Functional asplenia occurs only after 4 years of age in children with HbSC [43]. The pit count is a measure of splenic function in HbSC disease and values indicative of functional asplenia ( $>20 \%$ ) are higher than in other disorders [43]. The routine administration of prophylactic penicillin to infants and young children with $\mathrm{HbSC}$ disease may not be necessary due to persistence of splenic function. Chronic splenomegaly is another finding in $\mathrm{HbSC}$ disease and affects $35 \%$ of the children and $50 \%$ of adults. It can cause abdominal pain and cytopenia [44].

Acute splenic sequestration can occur when outflow obstruction of splenic sinusoids occurs with sickled red blood cells cause pooling of blood and massive splenomegaly. It can lead to rapid and painful splenomegaly and present with worsening anemia and decreasing platelet counts [44]. Low volume (about $5 \mathrm{ml} / \mathrm{kg}$ ) slow simple transfusion is the treatment for the condition and it should be understood that a rebound increase in the RBCs occur over hours to days due to the release of the red blood cells from the sinusoids as the sequestration resolves following the transfusion [45]. Role of splenectomy in splenic sequestration crisis and HbSC is debated as it can lead to paradoxical increase in viscosity and because problems associated with hyperviscosity [46].

\section{Renal Complications in Hemoglobin SC Disease}

Renal complications occur at a later stage when compared to HbSS in HbSC individuals. Glomerular hyperfiltration is more evident in HbSS compared to HbSC. Both Glomerular filtration rate and Creatinine Clearance were noted to be lower in HbSC when compared to HbSS. The spectrum of renal dysfunction seen in HbSC includes hyposthenuria, microalbuminuria, renal papillary necrosis and renal infarction $[46,47]$. End stage renal disease, even though reported in $2-3 \%$ of individuals with $\mathrm{HbSC}$, occurs later in life compared to HbSS. Renal papillary necrosis occurs more commonly in HbSC disease [40].

\section{Genitourinary Complications in Hemoglobin SC Disease}

Priapism is a well-documented complication in men with $\mathrm{HbSC}$ and is sometimes a presenting symptom. Erection lasting for more than 4 hours is a medical emergency and typically occurs in boys reaching sexual maturity. Penile erection is caused by the alternate contraction and vaso-relaxation of the penile cavernous tissue through the sympathetic and parasympathetic system, respectively. Several small molecules are also involved in the process, principal among them is Nitric Oxide (NO) through a cascade of events through its second messenger Cyclic Guanosine Monophosphate (cGMP) [48]. These provide important targets for therapy even though the exact mechanism has not been elucidated and multifactorial etiology is suspected [49,50]. The goal is prevention of erectile dysfunction and impotence. Treatment includes hydration, analgesics and use of alpha-adrenergic agonist and phosphodiesterase 5 inhibitors [51].

Surgical intervention like penile aspiration, irrigation with alpha adrenergic agonists like phenylephrine and, in severe recurrent cases, distal and proximal surgical shunting needs to be considered after urological consultation [51]. Control of overall severity of sickle cell disease related symptoms with Hydroxyurea (HU) may be helpful, but the role of HU for treatment of priapism is questioned due to lack of evidence [52]. The role of blood transfusion in amelioration of priapism is also questioned due to lack of evidence and the potential for neurological complication as noted in HbSS patients including severe headache, seizures, focal neurological deficits, and obtundation has been made called the ASPEN syndrome (Association of Sickle Cell Disease, Priapism, Exchange transfusion, and Neurologic Events) [53-55].

\section{Hepatobiliary disease in Hemoglobin SC disease}

Due to reduced hemolytic rates in HbSC disease, pigment stone formation and cholelithiasis has been found to be lower compared to HbSS disease. The reported rates have been somewhere between 5-20\% in HbSC individuals compared to 50\% in some cohorts with HbSS disease $[24,56]$. It has been found that co-inheritance of alpha thalassemia can reduce the severity of hemolytic complications and gall bladder disease in HbSC disease.

\section{Stroke in Hemoglobin SC Disease}

Stroke is a common complication of Sickle Cell Disease in children above 2 years of age. Prevelance of Stroke varies with the Sickle Cell Genotype with an age adjusted prevalence for $\mathrm{HbSS}$ at $4.01 \%, \mathrm{HbS} / \beta 0$ at $2.43 \%, \mathrm{HbS} / \beta+$ at $1.29 \%$, and $\mathrm{HbSC}$ at $0.84 \%$, respectively, at the time of study entry in the CSSD cohort. The chances of having a CVA by 20 years, 30 years and 45 years of age were estimated to be $11 \%, 15 \%$ and $24 \%$, respectively, but was significantly lower in the HbSC population at $2 \%, 4 \%$ and $10 \%$, respectively. According to the same report about $25 \%$ of patient with $\mathrm{HbSC}$ would have sustained stroke like changes by 60 years of age [57]. More recent studies have reported higher prevalence of stroke, especially silent stroke, in HbSC compared to the historical CSSD cohort [58,59]. At this time, it is not known if this higher prevalence is due to increased utilization of MRI imaging of the brain in this population.

Silent stroke, which is routinely not associated with overt neurological manifestations, seems to also occur in HbSC disease. Silent Stroke present bilaterally in 69\% and in the Frontal lobe in $85 \%$ of the cases. Transcranial Doppler monitors the blood velocity of patients with SCD allows the identification of those individuals at risk for stroke. Patients with Transcranial Doppler Ultrasound 
(TCD) values $>200 \mathrm{~cm} / \mathrm{sec}$ are at higher risk of developing stroke [60]. Unlike SS disease, TCD values for HbSC patients has not been well standardized, and the values tend to be lower in HbSC patients. Time Average Mean of Maximum (TAMM) velocities tend to be around $104.9 \mathrm{~cm} / \mathrm{sec}$ compared to $134.5+/-30.5 \mathrm{~cm} / \mathrm{sec}$ in HbSS patients [61,62]. Treatment considerations in $\mathrm{HbSC}$ will follow that of stroke in HbSS disease, even though there is a dearth of standardized diagnostic or treatment options. Both transfusion therapy and HU may be considered and is supported by small retrospective studies $[63,64]$.

There is also some evidence to support the practice of therapeutic phlebotomy to reduce hyperviscosity and thereby decrease the stroke risk in HbSC [64-66]. Even as TCD screening and chronic blood transfusions have decreased the incidence of stroke in $\mathrm{HbSS}$ disease, neither have been validated in $\mathrm{HbSC}$ disease.

\section{Thrombosis in Hemoglobin SC Disease}

There is an increased risk of thromboembolic events in HbSC disease. Individuals with $\mathrm{HbSC}$ had an increased expression of tissue factor, elevated thrombin- antithrombin complex and D-Dimer. Markers of endothelial activation like thrombomodulin and soluble vascular adhesion marker-1(VCAM-1) and inflammation (tumor necrosis factor- $\alpha$ ) were both significantly elevated in HbSC individuals when compared to healthy controls [67]. Higher Hemolytic Activity and Inflammation were associated with more intense activation of coagulation pathway and increased the thromboembolic complications associated with the disease.

Two of the more prevalent complications of the disease were associated with hemostatic activation- proliferative retinopathy and osteonecrosis [67]. Retrospective analysis has shown that individuals with $\mathrm{HbSC}$ are more prone to thrombotic complications compared to HbSS $[67,68]$. Everyone should be screened for arterial and venous thrombosis during routine visits even though SCD specific venous thromboprophylaxis does not exist at this time. Role of HU and other disease modifying agents in the prevention of thrombosis in HbSC disease is also not known at this time.

\section{Pregnancy in Hemoglobin SC Disease}

Again, most of the information regarding pregnancy in $\mathrm{HbSC}$ has been extrapolated from HbSS disease. Marginally delayed menarche has been noted in girls with HbSC [69]. Like with other forms of Sickle cell disease, women with HbSC experience more pregnancy related morbidity and mortality compared to normal controls. More sickle cell disease related, and non-related complications can occur during pregnancy including pain crisis, acute chest syndrome and urinary tract infections. In a Brazilian study, simple and exchange transfusion was conducted in pregnant $\mathrm{HbSC}$ women in the third trimester, but there is no significant evidence of its actual benefit in this group of women $[70,71]$.

\section{Diagnosis and Health Care Maintenance in Hemoglobin SC Disease}

Diagnosis is routinely made by the newborn screening program in the US and UK. Screening and confirmatory testing is conducted using isoelectric focusing and high-performance liquid chromatography. Due to population migration from areas where screening is not conducted, disease identification typically occurs when individuals present with complications of the disease. Duration of penicillin prophylaxis in children with HbSC is debated, due to continuation of adequate splenic function [72]. There is lack of good evidence supporting penicillin prophylaxis, but most centers prescribe Penicillin along the lines of prophylaxis guidelines for HbSS disease. Recommendation for vaccination also follows similar guidelines for HbSS disease.

\section{Role of Hydroxycarbamide in Hemoglobin SC Disease}

There is a paucity of data regarding use of hydroxyurea in HbSC disease. As a result, consensus guidelines are not available regarding its use in $\mathrm{HbSC} 1$. HU has been found to increase the MCV and $\mathrm{HbF}$ in SC disease without increasing the hematocrit. This has led to the reduction in vaso-occlusive episodes in SC subjects even though there is a lack of consensus regarding this approach to mitigate occlusive symptoms $[33,73]$. At a cellular level, there was evidence of increase in MCV after 8 weeks of therapy with HU. The proportion of dense cells was not significantly altered on HU therapy. There was also evidence of increased expression of red cell laminin receptor without evidence of adhesion to laminin. It has also been found to increase the HbF levels in the red cells.

A similar effect has not been seen with magnesium pirolate in the same study [33]. Investigators retrospectively looked at the effect of $\mathrm{HU}$ on HbSC and found that it was associated with a stable hemoglobin concentration; increased Fetal Hemoglobin ( $\mathrm{HbF}$ ) and Mean Corpuscular Volume (MCV); and reduced White Blood Cell Count (WBC), Absolute Neutrophil Count (ANC), and Absolute Reticulocyte Count (ARC). Reversible cytopenia's occurred in $22 \%$ of patients, primarily neutropenia and thrombocytopenia. Painful events were reduced with $\mathrm{HU}$, more in patients $>15$ years old [64]. A prospective single-center study of hydroxycarbamide in children with HbSC is ongoing (NCT02336373).

\section{Role of phlebotomy in reduction of Sickle Cell crisis in Hemoglobin SC disease}

Reduction of mean hemoglobin level through phlebotomy has been described as a method to reduce the sickle cell related crisis in HbSC disease. Both reduction in pain crisis and fewer hospitalized days has been noted in patient with HbSC when they are made iron deficient through phlebotomy with resultant reduction in hyperviscosity [74]. It has been hypothesized that by phlebotomy, the $\mathrm{HbS}$ levels were modulated and MCHC was reduced, leading to clinical benefits [66]. In symptomatic HbSC individuals with a 
hemoglobin $>10 \mathrm{gm} / \mathrm{dl}$, therapeutic phlebotomy to a hemoglobin of 9-10gm/dl maybe an important consideration for amelioration of clinical symptoms [34].

\section{Conclusion}

HbSC has been historically noted to be a milder variant of sickle cell disease, but emerging data shows that significant phenotypic variability occurs in this disease. Therapy related to HbSC is lacking and more studies are needed to understand phenotypic variability and therapeutic options in this condition which afflicts approximately $30 \%$ of the sickle cell disease population affected by this disease.

\section{Acknowledgement}

Author would like to thank Rosanna Spicer, MPH, for her editorial input.

\section{References}

1. Yawn BP, Buchanan GR, Annan A AN, Ballas SK, Hassell KL, et al. (2014) Management of sickle cell disease: summary of the evidence-based report by expert panel members. JAMA 312(10): 1033-1048.

2. Platt OS, Brambilla DJ, Rosse WF, Milner PF, Castro O, et al. (1994) Mortality in sickle cell disease. Life expectancy and risk factors for early death. N Engl J Med 330(23): 1639-1644.

3. Weatherall DJ (2010) The inherited diseases of hemoglobin are an emerging global health burden. Blood 115(22): 4331-4336.

4. Pecker LH, Schaefer BA, Jones LL (2017) Knowledge insufficient: the management of haemoglobin SC disease. Br J Haematol 176(4): 515-526.

5. Itano HA, Neel JV (1950) A new inherited abnormality of human hemoglobin. Proc Natl Acad Sci USA 36(11): 613-617.

6. Pauling L (1953) Abnormality of hemoglobin molecules in hereditary hemolytic anemias. Harvey Lect 49: 216-241.

7. St George RC, Pauling L (1951) The combining power of hemoglobin for alkyl isocyanides, and the nature of the heme-heme interactions in hemoglobin. Science 114(2972): 629-634.

8. Pauling L, Corey RB (1951) The polypeptide-chain configuration in hemoglobin and other globular proteins. Proc Natl Acad Sci USA 37(5): 282-285.

9. Pauling L (1948) The interpretation of some chemical properties of hemoglobin in terms of its molecular structure. Stanford Med Bull 6(1): 215-222.

10. Kaplan E, Zuelzer WW, Neel JV (1951) A new inherited abnormality of hemoglobin and its interaction with sickle cell hemoglobin. Blood 6(12): 1240-1249.

11. Widen AL, Cardon L (1961) Salmonella typhimurium osteomyelitis with sickle cell-hemoglobin C disease: a review and case report. Ann Intern Med 54: 510-521.

12. Powars DR (1991) Sickle cell anemia: beta s-gene-cluster haplotypes as prognostic indicators of vital organ failure. Semin Hematol 28(3): 202 208.

13. Powars DR (1991) Beta s-gene-cluster haplotypes in sickle cell anemia. Clinical and hematologic features. Hematol Oncol Clin North Am 5(3): 475-493.

14. Modiano D, Luoni G, Sirima BS, Simpore J, Verra F, et al. (2001) Haemoglobin C protects against clinical Plasmodium falciparum malaria. Nature 414(6861): 305-308.
15. Olson JA, Nagel RL (1986) Synchronized cultures of P falciparum in abnormal red cells: the mechanism of the inhibition of growth in HbCC cells. Blood 67(4): 997-1001.

16. Nagel RL, Fabry ME, Steinberg MH (2003) The paradox of hemoglobin SC disease. Blood Rev 17(3): 167-178.

17. Gualandro SF, Fonseca GH, Yokomizo IK, Gualandro DM, Suganuma LM (2015) Cohort study of adult patients with haemoglobin SC disease: clinical characteristics and predictors of mortality. $\mathrm{Br} \mathrm{J}$ Haematol 171(4): 631-637.

18. Rees DC, Thein SL, Osei A, Drasar E, Tewari S, et al. (2015) The clinical significance of $\mathrm{K}-\mathrm{Cl}$ cotransport activity in red cells of patients with HbSC disease. Haematologica 100(5): 595-600.

19. Hannemann A, Rees DC, Tewari S, Gibson JS (2015) Cation Homeostasis in Red Cells from Patients With Sickle Cell Disease Heterologous for HbS and HbC (HbSC Genotype). EBioMedicine 2(11): 1669-1676.

20. Bunn HF, Noguchi CT, Hofrichter J, Schechter GP, Schechter AN, et al. (1982) Molecular and cellular pathogenesis of hemoglobin SC disease. Proc Natl Acad Sci USA 79(23): 7527-7531.

21. Tripette J, Alexy T, Dessources HMD, Mougenel D, Beltan E, et al. (2009) Red blood cell aggregation, aggregate strength and oxygen transport potential of blood is abnormal in both homozygous sickle cell anemia and sickle-hemoglobin C disease. Haematologica 94(8): 1060-1065.

22. Wanek J, Gaynes B, Lim JI, Molokie R, Shahidi M (2013) Human bulbar conjunctival hemodynamics in hemoglobin SS and SC disease. Am J Hematol 88(8): 661-664.

23. Lemonne N, Lamarre $Y$, Romana M, Dessources HMD, Lionnet $F$, et al. (2014) Impaired blood rheology plays a role in the chronic disorders associated with sickle cell-hemoglobin C disease. Haematologica 99(5): 74-75.

24. Powars DR, Hiti A, Ramicone E, Johnson C, Chan L (2002) Outcome in hemoglobin SC disease: a four-decade observational study of clinical, hematologic, and genetic factors. Am J Hematol 70(3): 206-215.

25. Rezende PV, Belisario AR, Oliveira EL, Almeida JA, Oliveira LMM, et al. (2019) Co-inheritance of a-thalassemia dramatically decreases the risk of acute splenic sequestration in a large cohort of newborns with hemoglobin SC. Haematologica 104(7): 281-283.

26. McCurdy PR, Sherman AS (1978) Irreversibly sickled cells and red cell survival in sickle cell anemia: a study with both DF32P and 51CR. Am J Med 64(2): 253-258.

27. Wong WY, Zhou Y, Operskalski EA, Hassett J, Powars DR, et al. (1996) Hematologic profile and lymphocyte subpopulations in hemoglobin SC disease: comparison with hemoglobin SS and black controls. The Transfusion Safety Study Group. American journal of hematology 52(3): 150-154.

28. Lamarre Y, Dessources HMD, Romana M, Mistrih LML, Waltz X, et al. (2014) Relationships between systemic vascular resistance, blood rheology and nitric oxide in children with sickle cell anemia or sickle cell-hemoglobin C disease. Clin Hemorheol Microcirc 58(2): 307-316.

29. Mockesch B, Charlot K, Jumet S, Romana M, Doumdo DL, et al. (2017) Micro- and macrovascular function in children with sickle cell anaemia and sickle cell haemoglobin C disease. Blood Cells Mol Dis 64: 23-29.

30. Hannemann A, Weiss E, Rees DC, Dalibalta S, Ellory JC, et al. (2011) The Properties of Red Blood Cells from Patients Heterozygous for HbS and HbC (HbSC Genotype). Anemia 2011: 248527.

31. Waltz X, Pichon A, Mougenel D, Lemonne N, Mistrih LML, et al. (2012) Hemorheological alterations, decreased cerebral microvascular oxygenation and cerebral vasomotion compensation in sickle cell patients. Am J Hematol 87(12): 1070-1073.

32. Lionnet F, Hammoudi N, Stojanovic KS, Avellino V, Grateau G, et al. (2012) Hemoglobin sickle cell disease complications: a clinical study of 179 cases. Haematologica 97(8): 1136-1141. 
33. Wang W, Brugnara C, Snyder C, Wynn L, Rogers Z, et al. (2011) The effects of hydroxycarbamide and magnesium on haemoglobin SC disease: results of the multi-centre CHAMPS trial. British journal of haematology 152(6): 771-776

34. Bouchair N, Manigne P, Kanfer A, Raphalen P, de Montalembert M, et al. (2000) [Prevention of sickle cell crises with multiple phlebotomies] Arch Pediatr 7(3): 249-255.

35. Rombos Y, Tzanetea R, Kalotychou V, Konstantopoulos K, Simitzis $S$, et al. (2002) Amelioration of painful crises in sickle cell disease by venesections. Blood Cells Mol Dis 28(2): 283-287.

36. Lutty GA, Taomoto M, Cao J, McLeod DS, Vanderslice P, et al. (2001) Inhibition of TNF-alpha-induced sickle RBC retention in retina by a VLA 4 antagonist. Invest Ophthalmol Vis Sci 42(6): 1349-1355.

37. Myint KT, Sahoo S, Thein AW, Moe S, Ni H (2015) Laser therapy for retinopathy in sickle cell disease. Cochrane Database Syst Rev (10): 010790.

38. Carraro MC, Cappellini MD, Gerli GC (1998) Hemoglobin SC disease and proliferative retinopathy. Haematologica 83(10): 944-945.

39. Leveziel N, Garin SB, Lalloum F, Querques G, Benlian P, etal. (2011) Clinical and laboratory factors associated with the severity of proliferative sickle cell retinopathy in patients with sickle cell hemoglobin C (SC) and homozygous sickle cell (SS) disease. Medicine Baltimore 90(6): 372-378.

40. Drawz P, Ayyappan S, Nouraie M, Saraf S, Gordeuk V, et al. (2016) Kidney Disease among Patients with Sickle Cell Disease, Hemoglobin SS and SC. Clin J Am Soc Nephrol 11(2): 207-215.

41. McKinney CM, Siringo F, Olson JL, Capocelli KE, Ambruso DR, et al. (2015) Red cell exchange transfusion halts progressive proliferative sickle cell retinopathy in a teenaged patient with hemoglobin SC disease. Pediatr Blood Cancer 62(4): 721-723.

42. Saito N, Watanabe M, Liao J, Flower EN, Nadgir RN, et al. (2011) Clinical and radiologic findings of inner ear involvement in sickle cell disease. AJNR Am J Neuroradiol 32(11): 2160-2164.

43. Lane PA, O'Connell JL, Lear JL, Rogers ZR, Woods GM, et al. (1995) Functional asplenia in hemoglobin SC disease. Blood 85(8): 2238-2244.

44. Zimmerman SA, Ware RE (2000) Palpable splenomegaly in children with haemoglobin SC disease: haematological and clinical manifestations. Clin Lab Haematol 22(3): 145-150.

45. Aquino VM, Norvell JM, Buchanan GR (1997) Acute splenic complications in children with sickle cell-hemoglobin C disease. J Pediatr 130(6): 961965.

46. Brousse V, Elie C, Benkerrou M, Odièvre MH, Lesprit E, et al. (2012) Acute splenic sequestration crisis in sickle cell disease: cohort study of 190 paediatric patients. British journal of haematology 156(5): 643-648.

47. Powars DR, Elliott Mills DD, Chan L, Niland J, Hiti AL, et al. (1991) Chronic renal failure in sickle cell disease: risk factors, clinical course, and mortality. Ann Intern Med 115(8): 614-620.

48. Burnett AL, Musicki B (2005) The nitric oxide signaling pathway in the penis. Curr Pharm Des 11(31): 3987-3994.

49. Burnett AL (2009) Against: No surgery for stuttering priapism. J Urol 181(2): 450-451

50. Burnett AL (2008) Molecular pharmacotherapeutic targeting of PDE5 for preservation of penile health. J Androl 29(1): 3-14

51. Olujohungbe A, Burnett AL (2013) How I manage priapism due to sickle cell disease. British journal of haematology 160(6): 754-765.

52. Saad ST, Lajolo C, Gilli S, José Francisco C. Marques Jr, et al. (2004) Followup of sickle cell disease patients with priapism treated by hydroxyurea. American journal of hematology 77(1): 45-49.
53. Merritt AL, Haiman C, Henderson SO (2006) Myth: blood transfusion is effective for sickle cell anemia-associated priapism. CJEM 8(2): 119-122.

54. Siegel JF, Rich MA, Brock WA (1993) Association of sickle cell disease, priapism, exchange transfusion and neurological events: ASPEN syndrome. J Urol 150(5): 1480-1482.

55. Rackoff WR, Frempong OK, Month S, Scott JP, Neahring B, et al. (1992) Neurologic events after partial exchange transfusion for priapism in sickle cell disease. J Pediatr 120(6): 882-885.

56. Walker TM, Hambleton IR, Serjeant GR (2000) Gallstones in sickle cell disease: observations from The Jamaican Cohort study. J Pediatr 136(1): 80-85

57. Frempong OK, Weiner SJ, Sleeper LA, Miller ST, Embury S, et al. (1998) Cerebrovascular accidents in sickle cell disease: rates and risk factors. Blood 91(1): 288-294.

58. Guilliams KP, Fields ME, Hulbert ML. (2015) Higher-than-expected prevalence of silent cerebral infarcts in children with hemoglobin SC disease. Blood 125(2): 416-417.

59. Sathi BK, Yoshida Y, Michael RW, Nolan LW, Gruner B, et al. (2019) Unusually High Prevalence of Silent Stroke and Cerebral Vasculopathy in Hemoglobin SC Disease. Blood 134(1): 2276.

60. Hankins JS, Fortner GL, McCarville MB, Smeltzer MP, Wang WC, et al. (2008) The natural history of conditional transcranial Doppler flow velocities in children with sickle cell anaemia. Bj haematology 142(1): 94-99.

61. Santiago RP, Vieira C, Adanho CSA, Santana SS, Guarda CC, et al. (2017) Laboratory and Genetic Biomarkers Associated with Cerebral Blood Flow Velocity in Hemoglobin SC Disease. Dis Markers 2017: 11.

62. Vieira C, de Oliveira CN, de Figueiredo LA, Santiago RP, Adanho CSA, et al. (2017) Transcranial Doppler in hemoglobin SC disease. Pediatr Blood Cancer 64(5): 26342

63. Fridlyand D, Wilder C, Clay ELJ, Gilbert B, Pace BS (2017) Stroke in a Child with Hemoglobin SC Disease: A Case Report Describing use of Hydroxyurea after Transfusion Therapy. Pediatr Rep 9(1): 6984.

64. Jones LL, Pressel S, Hilliard L, Brown RC, Smith MG et al. (2016) Effects of hydroxyurea treatment for patients with hemoglobin SC disease. American journal of hematology 91(2): 238-242.

65. Summarell CC, Sheehan VA (2016) Original Research: Use of hydroxyurea and phlebotomy in pediatric patients with hemoglobin SC disease. Exp Biol Med Maywood 241(7): 737-744.

66. Markham MJ, Lottenberg R, Zumberg M (2003) Role of phlebotomy in the management of hemoglobin SC disease: case report and review of the literature. American journal of hematology 73(2): 121-125.

67. Colella MP, de Paula EV, Machado Neto JA, Conran N, Bizzacchi JMA, et al. (2015) Elevated hypercoagulability markers in hemoglobin SC disease. Haematologica 100(4): 466-471.

68. Lionnet F (2013) Venous and arterial viscosity-associated thrombosis in hemoglobin SC disease. Am J Med 126(10): 13

69. Serjeant GR, Hambleton I, Thame M (2005) Fecundity and pregnancy outcome in a cohort with sickle cell-haemoglobin $\mathrm{C}$ disease followed from birth. BJOG 112(9): 1308-1314.

70. Ntim OE, Meeks D, Seed PT, Webster L, Howard J, et al. (2015) Adverse maternal and perinatal outcomes in pregnant women with sickle cell disease: systematic review and meta-analysis. Blood 125(21): 33163325 .

71. Benites BD, Benevides TC, Valente IS, Marques JFJr, Gilli SCO, et al. (2016) The effects of exchange transfusion for prevention of complications during pregnancy of sickle hemoglobin $\mathrm{C}$ disease patients. Transfusion 56(1): 119-124 
72. Rogers ZR, Buchanan GR (1995) Bacteremia in children with sickle hemoglobin $C$ disease and sickle beta $(+)$-thalassemia: is prophylactic penicillin necessary? J Pediat 127(3): 348-354.

73. Yates AM, Dedeken L, Smeltzer MP, Lebensburger JD, Wang WC, et al. (2013) Hydroxyurea treatment of children with hemoglobin SC disease. Pediatr Blood Cancer 60(2): 323-325.
74. Castro O, Poillon WN, Finke H, Massac E (1994) Improvement of sickle cell anemia by iron-limited erythropoiesis. American journal of hematology 47(2): 74-81. 